\title{
Evaluation of the Outcomeof Preservation of Intercostobrachial Nerve during Axillary Lymph Node Dissection
}

\author{
H.R.Mussalam, E.M.Kilany, M.S.Kharoub and M.A.Saadoun \\ General Surgery Dept., Faculty of Medicine, Benha Univ., Benha, Egypt \\ Email:dr_Mohammed@yahoo.com.
}

\begin{abstract}
One in each eight ladies created bosom malignancy of which roughly $60 \%$ are to be dealt with carefully for essential bosom tumor resection and axillary lymph node(L.N) arranging. The point of this postulation is to assess the useful and oncological noteworthiness of conservation of intercostobrachial nerve during axillary lymph hub analyzation in instances of bosom malignancy and its effect on Post Mastectomy Pain Syndrome. forty patients were remembered for this imminent investigation were devided into 2 equivalent gatherings. 20 patients were incorporated into the ICBN conservation bunch A. In gathering B, 20 patients were incorporated as control where this nerve was separated. In all the cases, ICBN was recognized intraoperatively. The torment appraisal was done on the first day, following multi month and following 3 months post-operatively. It was discovered that, $75 \%$ of the patients were asymptomatic following 3 months of follow up in ICBN safeguarding gathering (bunch A) and 60\% in the nerve segment gathering (bunch B ) $(\mathrm{p}<0.01)$. There was a slight expansion in the all out season of a medical procedure in gathering $A$, however it was not huge and there was likewise no critical distinction in the quantities of axillary lymph hubs analyzed between the two gatherings. safeguarding of ICBN is an attainable and astute approach to diminish PMPS in bosom malignancy patients without bargaining usable time or nearby pace of repeat.
\end{abstract}

Key Words : Intercostobrachia, Axillary lymph node, Breast cancer.

\section{Introduction}

Around the world, bosom malignancy is the main sort of disease in ladies, representing $25 \%$, all things considered [1]. One in each eight ladies created bosom disease of which roughly $60 \%$ are to be dealt with carefully for essential bosom tumor resection and axillary lymph node(L.N) organizing [2].

The innervation of the cutaneous and subcutaneous structures of the bosom is with substantial and preganglionic indicative innervation being provided through the average and parallel cutaneous parts of the ventral ramus of the third through 6th intercostal ramus. The sidelong cutaneous part of the second intercostals nerve (intercostobrachial nerve) crosses the axilla to innervate the upper average segment of the arm, axilla, and a piece of the foremost chest divider. Axillary analyzation for bosom malignant growth presents dangers to the intercostobrachial nerve (ICBN) from extends just as from plain exchange. Regarding prior investigation directed by cunnick there are six anatomical variety of intercostobrachial nerve [3].

Constant neuropathic torment after a medical procedure for bosom malignancy is a typical issue with pervasiveness rates going from $20-65 \%$. [4].

Four distinct kinds of ongoing neuropathic torment following bosom malignant growth because of careful injury [5].

- Ghost Breast Pain is knowledgeable about the territory of the eliminated bosom.

- Intercostobrachial Neuralgia torment is frequently went with tangible changes in the dispersion of the intercostobrachial nerve.

- Neuroma torment (counting scar torment) is the torment in the district of a scar on the bosom, chest, or arm that is incited or exacerbated by percussion.
- Other nerve injury torment results from harm to the average/sidelong pectoral, long thoracic or thoracodorsal nerve. Intercostobrachial nerve injury should be the primary driver [6].

Studies done by before scientists expressed that Preservation of Intercostobrachial nerve during adjusted extremist mastectomy prompts factually critical abatement in the postoperative tangible side effects including deadness and neuropathic torment and Successful conservation of Intercostobrachial nerve conceivable in dominant part of patient [7].

The point of this postulation is to assess the useful and oncological hugeness of safeguarding of intercostobrachial nerve during axillary lymph hub analyzation in instances of bosom malignant growth and its effect on Post Mastectomy Pain Syndrome.

\section{Patient and method}

This is a prospective comparative study

on 40 female patients having cancer breast and underwent axillary L.N dissection either as a part of modified radical mastectomy or during conservative breast surgery

The patient was divided in 2 groups:-

- Group (A): ICBN was preserved during axillary dissection.

- Group (B): ICBN was divided during axillary dissection.

\section{Inclusion criteria}

Patient had cancer breast with the following criteria:-

- Unilateral disease

- Early disease (up to stage IIB)

- Biopsy or FNAC proven breast carcinoma

- No previous axillary surgery 
Lymph nodes were considered positive if they were clinically enlarged or using sentinel L.N technique

\section{Exclusion criteria}

- Advanced disease (beyond stage IIB)

- Bilateral and recurrent diseases

- Lost in follow up

- Patients received neo adjuvant chemotherapy or radiotherapy

- Angina pectoris

- Patient refused participation

- Diabetic patient with preoperative complain of diabetic neuropathy

- Any patient with upper limb neurological problem causing chronic upper limb pain as cervical disc prolapse

In gathering $\mathrm{A}$ the intercostobrachial nerve that rises up out of the subsequent intercostal space and enters the example was protected .

In gathering $\mathrm{B}$ the intercostobrachial nerve was partitioned .

After medical procedure, the two gatherings were assessed on the subsequent day, first month and in the third month post operatively then the result was assessed with respect to :-

\section{Post employable torment}

Chronic torment was characterized as any sort of agony in ipsilateral bosom, chest divider, shoulder, arm or axillary area, enduring for in any event 3 months after end of a medical procedure and adjuvant treatment.

Torment attributes were surveyed in detail utilizing the Short Form McGill Pain Questionnaire (SFMPQ).It is a 15-thing type of the more McGill Pain poll. The SF-MPQ comprise of 15 descriptors (11 tactile; 4 full of feeling) which are appraised on a 4 point force scale as 0 -none., 1-gentle, 2.moderate or $3=$ severe

Three torment scores are gotten from the amount of the power rank estimations of the words decided for tangible, emotional and all out descriptors. The SFMPQ additionally incorporates the Present Pain Intensity (PPI) list of the standard MPQ and as visual simple scale (VAS).

2- Lymphedema

3- Numbers of L.N and oncological outcome

\section{Results}

Table (1) Pain score in the studied groups.
In this study, $17(42.5 \%)$ female patients having cancer breast on right side (in 9 of them ICBN was preserved during axillary dissection \& 7 of them ICBN was divided during axillary dissection ) and 23(57.5\%) female patients having cancer breast on left side (in 11 of them ICBN was preserved during axillary dissection \& 12 of them ICBN was divided during axillary dissection ).

Chi-square test was performed to detect the level of significance between both groups regarding side of mass which demonstrated that there was no significant difference between both groups regarding side of mass

In this study, 30 (75\%) patients underwent axillary L.N dissection as a part of modified radical mastectomy (in 15 of them ICBN was preserved during axillary dissection \& 15 of them ICBN was divided during axillary dissection ) and 10 (25\%) female patients underwent axillary L.N dissection as a part of conservative breast surgery (in 5 of them ICBN was preserved during axillary dissection \& 5 of them ICBN was divided during axillary dissection ).

There was no significant difference between both groups

The age of the patients in group (A) ranged between 33 and 65 years old. With a mean of 46.60 years and SD 9.25

The age of the patients in group (B) ranged between 31 and 65 years old. With a mean of 47.20 years and SD 10.42 .

There was no significant difference between both groups regarding age

Lymphedema was found only in four cases from all cases $(10 \%)$ two cases in each group.

There was no significant difference between both groups

In group (A) the median of total dissected $\mathrm{LN}$ was 11 (9-14.5) and positive LN was 4 (1.5-4).

In group (B) the median of total dissected $\mathrm{LN}$ was 13 (10.5-15) and positive LN was 5 (3-6.5).

There was no significant difference between both groups

The preservation of the intercostobrachial nerve during axillary dissection in patients with breast cancer resulted in a significant reduction in paraesthesias, numbness and pain at 3 months as compared with the standard dissection in which the nerve is routinely sacrificed.

Comparison of mean pain score at 24 hours, 1 month, and 3 months between group A and group B is shown in Table $(1,2)$.

\begin{tabular}{|c|c|c|c|c|c|c|}
\hline \multirow[t]{2}{*}{ Pain score } & & $\begin{array}{c}\text { Group A } \\
\text { (Preserved ICBN) } \\
\end{array}$ & $\begin{array}{c}\text { Group B } \\
\text { (Sacrificed ICBN) } \\
\end{array}$ & \multirow[t]{2}{*}{ Test value $\neq$} & \multirow[t]{2}{*}{ P-value } & \multirow[t]{2}{*}{ Sig. } \\
\hline & & No. $=20$ & No. $=20$ & & & \\
\hline & Mean \pm SD & $2.1 \pm 0.64$ & $2.35 \pm 0.49$ & & & \\
\hline 1st day & $\begin{array}{l}\text { Median (IQR) } \\
\text { Range }\end{array}$ & $\begin{array}{c}2(2-2.5) \\
1-3\end{array}$ & $\begin{array}{c}2(2-3) \\
2-3\end{array}$ & -1.252 & 0.211 & NS \\
\hline 1st month & $\begin{array}{c}\text { Mean } \pm \text { SD } \\
\text { Median (IQR) } \\
\text { Range }\end{array}$ & $\begin{array}{c}0.4 \pm 0.5 \\
0(0-1) \\
0-1\end{array}$ & $\begin{array}{c}0.55 \pm 0.69 \\
0(0-1) \\
0-2\end{array}$ & -0.559 & 0.576 & NS \\
\hline
\end{tabular}




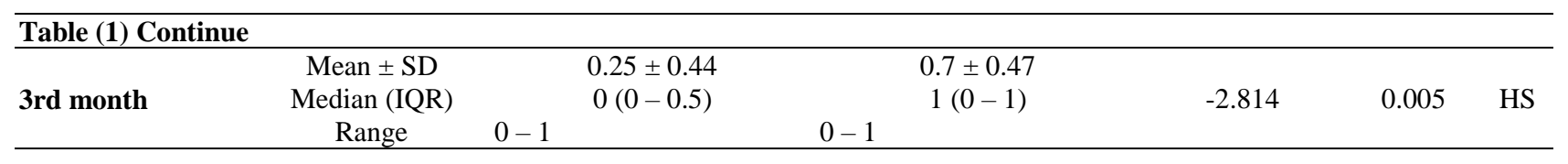

P-value > 0.05: Non significant; P-value < 0.05: Significant; P-value $<0.01$ : Highly significant

Table (2) Parathesia \& numbness in the studied groups.

\begin{tabular}{|c|c|c|c|c|c|}
\hline \multirow[t]{2}{*}{ Pain score } & & $\begin{array}{c}\text { Group A } \\
\text { (Preserved ICBN) }\end{array}$ & $\begin{array}{c}\text { Group B } \\
\text { (Sacrificed ICBN) }\end{array}$ & \multirow[t]{2}{*}{ P-value } & \multirow[t]{2}{*}{ Sig. } \\
\hline & & No. $=20$ & No. $=20$ & & \\
\hline \multirow{3}{*}{ Parathesia } & 1st day & 0 & 0 & 1 & NS \\
\hline & $1 \mathrm{st}$ month & 5 & 5 & 1 & NS \\
\hline & 3rd month & 5 & 15 & $<0.001$ & HS \\
\hline \multirow{3}{*}{ Numbness } & 1 st day & 0 & 0 & 1 & NS \\
\hline & 1 st month & 5 & 5 & 1 & NS \\
\hline & 3rd month & 5 & 15 & $<0.001$ & HS \\
\hline
\end{tabular}

\#: Mann-Whitney test

The mean pain score recorded at 24 hours for group A and group B was the same, no statistical significant difference between the two groups. Similarly at 1 month, no difference had been found in pain score in both groups of ICBN. However there is significant decrease of pain, numbness and paraesthesia in group A as compared with group $\mathrm{B}$ at 3 month $(\mathrm{P}<0.001)$. This shows that over a period time ( 3 months) the pain was significantly decreased in group A as compared with group B.

\section{Discussion}

To secure the nerve, the axillary substance are first reflected off the axillary vessels medially, and the analyzation continues poorly and posteriorly in the average axilla. The ICBN is regularly experienced before the long thoracic nerve is recognized. The ICBN is then dismembered liberated from the greasy axillary tissues until it enters the average arm in the locale where the axillary vein crosses the ligament of latissimus dorsi.

In the current examination the length of follow up was as long as 3 months which demonstrated critical distinction in the torment score of the ICBN protected classification $(\mathrm{p}=<0.001$ at 3 months). Anyway deadness and Paraesthesia likewise show critical contrast at 3 months. Patients grumbling deadness toward the finish of 3 months in the ICBN safeguarded classification was (20\%) quiet as contrasted and non saved ICBN gathering (80\%). Paraesthesia toward the finish of 3 months in ICBN protected class was (20\%) as contrasted and non safeguarded gathering (80\%) with $(p=0.001)$. This shows a critical reduction of deadness and paresthesia following 3 months of medical procedure.

In 1985 Temple et al did an investigation of the 50 patient with stage 1 bosom malignancy with safeguarding of intercostobrachial nerve; just 2 among these had stamped tangible misfortunes. 95 percent of these patients had generally ordinary sensation. The zone of most serious danger for tangible change in these patients was in the locale of the back axillary crease (32 percent). None of these patients griped of postoperative dysesthesias or paraesthesias. Mean length of development was 29 months with a scope of 6 to 60 months. No patient had a territorial repeat of malignant growth regardless of the way that 33 percent of these patients had included hubs [8].

In 1998 Abdullah, et al examined the achievability and advantage of safeguarding the ICBN. Saving the ICBN was achievable in 39 (65 percent) of the 60 patients randomized to the protection gathering. Protecting the nerve delayed the methodology by a middle of $5 \mathrm{~min}$. No distinction in tangible manifestations between the gatherings was seen at 3 months. At 3 months 53 percent of patients randomized to ICBN safeguarding had a tactile shortfall contrasted and 84 percent of those randomized to ICBN penance $(\mathrm{P}<$ or $=0.05)$ [9]. He presumed that protecting the ICBN lessens the rate of tangible shortfall (yet not indications) in patients after axillary leeway. Anyway in this investigation, a huge distinction in tangible indications (deadness) between the gatherings was seen at 3 months $(\mathrm{p}<0.001)$.

The current examination likewise shows that protection of intercostobrachial nerve decline the torment, deadness and paresthesia .

Inconveniences of axillary medical procedure for bosom disease and whether protection intercostobrachial nerve (ICBN) lessens post mastectomy torment was concentrated by Kim $\mathrm{O}$. Taylor et al in 2003 directed an examination and 100 and seventy of $208(82 \%)$ surveys were returned finished. At any rate one indication was accounted for by $130(76.5 \%)$ of patients. Deadness was the most well-known indication, present in $60 \%$ generally speaking. Patients who had the ICBN protected announced altogether less deadness $(37.5 \%$ versus $71.7 \% \mathrm{P}<0.001)$. Agony was available in $45.3 \%$ of patients and those with the ICBN protected had 
essentially less torment $(31.3 \%$ versus $58.5 \% \mathrm{P}=0.02)$ [10].

While in the current examination it found that agony diminishes continually over the post usable period as is clear from the mean estimations of the torment scores. There was huge distinction in the agony at 24 hours $(\mathrm{p}=0.12)$ and a half year $(\mathrm{p}=$ $<0.001$ ) long periods of follow up.

Different investigations demonstrating huge lessening in torment subsequent to saving intercostobrachial nerve were directed by Wei et al in 2005 who examined the clinical benefit of protecting ICBN during the axillary lymph hubs extraction in bosom malignant growth activities. According to their investigation 100 and 62 instances of stages I, II and IIIa bosom malignancy patients were protected in exploratory gathering and not in benchmark group. The two gatherings were dealt with following the training rule of bosom malignancy, and found no repeat during 4 to three years following up. The postoperative arm tangible circulation was $22.2 \%$ in exploratory gathering, which was additionally altogether not quite the same as that of control bunch $31.1 \%$ (chi (2) = 7.86, $\mathrm{p}<0.01)$ [11].

In correlation, this investigation was restricted to 40 patients having $\mathrm{T} 1$ and $\mathrm{T} 2$ injury and we inferred that there was huge contrast in agony in the saved gathering when contrasted with non-safeguarded bunch throughout timeframe. Despite the fact that torment diminished continually over the post usable period as apparent from the mean estimations of the agony scores. Use of chi square demonstrated that there was huge agony distinction at 3 months $(\mathrm{p}<0.001)$ of follow up, while there was likewise critical contrast in Paraesthesia and deadness in the saved gathering when contrasted with non-safeguarded gathering of ICBN.

In 2007, Ivanovic et al examined the ramifications of the part of the neurovascular components going through the analyzed tissue (ICBN) in traditional axillary analyzation in bosom malignancy medical procedure. It was a forthcoming report in which 126 patients going through axillary hub leeway for bosom malignancy of stages I and II were arbitrarily chosen for protection of ICBN. Tangible shortfall, torment were analyzed in the initial fourteen days after the medical procedure. No distinction in the quantity of dismembered hubs was seen between the two gatherings $(p=0.7)$. The deficiency of affectability was altogether more uncommon in the gathering randomized for ICBN conservation (16/65 versus $30 / 61, \mathrm{p}<0.005)$, while there was no distinction in the agony force and term (49/65 versus 44/61, p>0.05) [7].

Later on, Verma et al did review concentrate in 2011 to assess the job of conservation of the intercostobrachial nerve and post-mastectomy torment condition and furthermore to assess different anatomical varieties of the intercostobrachial nerve. 42 patients were incorporated into the ICB nerve safeguarding bunch A. In Group B, 27 patients were incorporated where this nerve was segmented. In all the cases, it was attempted to distinguish the nerve and its course at the best to survey different varieties. The abstract and target torment assessments were performed on the second day, following multi month and following 3 months post-operatively. Following 3 months, $76.2 \%$ of the patients were asymptomatic in Group A (ICB nerve conservation gathering) and $51.9 \%$ in the nerve area gathering (Group B) $(p<.01)$. Despite the fact that there was a slight expansion in the all out season of a medical procedure in gathering $\mathrm{A}$, it was not critical $(\mathrm{p}=0.62)$ [12].

In 2003 Freeman et al did an investigation to evaluate long haul aftereffects of protection of the intercostobrachial nerve. Follow up was at around 3 years post-operatively (range 32-38 months) at which time 16 patients had kicked the bucket, two were known to have metastatic sickness and were avoided and seven had been lost to catch up. The excess 95 patients were sent a letter mentioning participation at a center and a survey getting some information about their present indications. He found that there was no distinction in constraint of every day exercises, shoulder firmness or Neuroma arrangement. Looking at really protected and isolated gatherings the patient evaluation of 'various sensation' contrasted $(p=0.006)$ and the all out territory of strange sensation was essentially particular between the two gatherings with a more modest region of tangible misfortune in the really saved gathering $(\mathrm{p}=0.009)$ [13].

In this examination there was huge distinction between the two gatherings at 3 months in regard to Paraesthesia and deadness. At multi month all the patients in non protected gathering and safeguarded bunch didn't grumbled deadness and paresthesia. At 3 months $(80 \%)$ in non protected gathering had deadness when contrasted with $(20 \%)$ in saved gathering of ICBN. Likewise $(75 \%)$ in non-saved gathering had paresthesia when contrasted with $(25 \%)$ in protected gathering of ICBN following 3 months $(\mathrm{p}=0.005)$ which shows that both deadness our In investigation there was huge distinction between the two gatherings at 1 and 3 months in regard to Paraesthesia and deadness.

In this examination, we have likewise discovered the huge diminishing in torment, deadness and paraesthesias after the 3 months in saved gathering of ICBN.

The working specialist should know about these different anatomical variations of the ICBN while working so that there are less odds of penance of ICBN. Along these lines it should be a normal practice to save the ICBN at the hour of axillary medical procedure as it essentially decreases the patient's dismalness and improves the personal satisfaction.

This examination shows that the dreariness coming about because of division of the ICBN during axillary medical procedure is huge. Protecting ICBN essentially diminishes Paraesthesia, deadness and torment. 


\section{Conclussion}

preservation of ICBN is a feasible and wise way to decrease PMPS in breast cancer patients without compromising operative time or local rate of recurrence.

\section{References}

[1] Lipworth. Epidemiology of breast cancer. Eur J Cancer, Vol.4, PP.7-30,1995.

[2] M.A.Warmuth , G.Bowen , L.R.Prosnitz. Complications of axillary lymph node dissection for carcinoma of the breast: a report based on a patient survey. Cancer, Vol.83, PP.1362-8,1998.

[3] G.H.Cunnick, S.Upponi, G.C.Wishart. Anatomical variants of the intercostobrachial nerve encountered during axillary dissection. The Breast, Vol.10, PP.160- 2,2001.

[4] M.S.Wallace, A.MWalles, J.Lee . Pain After Breast Surgery. A Survey of 282 Women. Pain , Vol.66(2-3), PP.195-205,1996.

[5] B.F.Jung , G.M.Ahrendt , A.L.Oaklander . Neuropathic pain following breast cancer surgery: proposed classification and research update. Pain, Vol.104, PP.1-13,2003.

[6] W.C.Smith , D.Bourne , J.Squair. A retrospective cohort study of post mastectomy pain syndrome. Pain, Vol. 83, PP.91-5,1999.

[7] N.Ivanovic , M.Granic , T.Randelovic . Functional effects of preserving the intercostobrachial nerve and the lateral thorathic vein during axillary dissection in breast cancer conservative surgery.Vojnosanit Pregl , Vol.64, PP.195$198,2007$.

[8] W.J.Temple, A.S.Ketcham. Preservation of the intercostobrachial nerve during axillary dissection for breast cancer. Am J Surg, Vol.150, PP.585588,1985 .

[9] T.I.Abdullah, J.Iddon, L.Barr. Prospective randomized controlled trial of preservation of the intercostobrachial nerve during axillary node clearance for breast cancer. Br J Surg, Vol. 85, PP.1443-1445, 1998 .

[10] K.O.Taylor. Morbidity associated with axillary surgery for breast cancer. ANZJ Surg, Vol. 74, PP. 314-317,2004

[11] W.D.Wei, X.Wang, T.H.Rong. Methods of preserving intercostobrachial nerve during breast cancer operation and its clinical value. Zhonghua Wai Ke Za Zhi. vol.43, PP.1136-1138,2005.

[12] S.Verma, S.Kala, R.Bhargava. Evaluation of the role of preservation of the intercostobrachial nerve on the post-mastectomy pain syndrome in breast cancer patients of north India. The internet $\mathbf{J}$ of surgery, Vol.23, PP. 1, 2011.

[13] S.R.M.Freeman, S.J.Washington, T.Pritchard. Long term results of a randomized prospective study of preservation of the intercostobrachial nerve. European J.,Surgical Oncology, Vol. 29, PP. 213-215,2003. 